\title{
S100A14 protein as diagnostic and prognostic marker in hepatocellular carcinoma
}

\author{
Basma Fathy Mohamed ${ }^{1 *}$, Waleed Mohamed Serag ${ }^{2}$, Reda Mahamoud Abdelal ${ }^{3}$ and Heba Fadl Elsergany ${ }^{4}$
}

\begin{abstract}
Background: Protein S100A14 has recently been implicated in the progress of several types of cancers. This study aimed to investigate the clinical significance of S100A14 in the diagnosis of hepatocellular carcinoma (HCC).

Results: S100A14 was significantly elevated in the HCC group. A cut-off value for serum S100A14 between the HCC group and cirrhosis group is $>0.47$ with a sensitivity of $100 \%$ and specificity of $88.57 \%$. S100A14 level was a significant diagnostic factor for HCC and a good reference for HCC progression.
\end{abstract}

Conclusion: These results suggest that S100A14 is a good diagnostic marker for HCC.

Keywords: Hepatocellular carcinoma, Cirrhosis, S100A14

\section{Background}

Hepatocellular carcinoma is the fifth most frequently diagnosed cancer in adult men worldwide and is the second leading cause of cancer-related death in the world [1]. The primary etiology of $\mathrm{HCC}$ is cirrhosis resulting from chronic infection by the hepatitis $\mathrm{B}$ virus and hepatitis $\mathrm{C}$ virus as well as alcoholic or non-alcoholic liver injury [2]. More than $80 \%$ of HCC cases are from the Asian and African continents, and more than $50 \%$ of cases are from mainland China with a majority of viral hepatitis patients [3].

Hepatocellular carcinoma diagnosis has relied on several tools combining imaging techniques and the measurement of serum alfa-fetoprotein (AFP) [4]. Although both ways are relatively efficient for large tumors, the specificity of serum AFP is low, especially against a background of chronic hepatitis [5]. The elevation of AFP occurs in hepatocytes regeneration, hepatocarcinogenesis, and embryonic carcinomas [6, 7]. Alpha-fetoprotein determination lacks adequate sensitivity and specificity for effective surveillance and for diagnosis $[8,9]$. Thus, the identification of new markers for HCC with high sensitivity and specificity is essential [10].

\footnotetext{
* Correspondence: basma.fathy24@gmail.com

${ }^{1}$ Biochemist, Suez Hospital for Health Insurance, Suez, Egypt

Full list of author information is available at the end of the article
}

The S100 protein family has been reported to contribute to multiple biological processes, such as growth, cell motility, signal transduction, transcription, cell survival, and apoptosis, which are related to normal development and tumorigenesis [11]. S100 proteins, a large subgroup of the EF-hand (helix-loop-helix structural domain) protein family, are small calcium-binding proteins that have a broad range of intracellular and extracellular functions [12]. S100 proteins belong to a large subgroup of 25 small, acidic proteins that are characterized by distinctive homo-or hetero-dimeric architecture and EF-hand Ca2+-binding motifs, and are expressed in a variety of cell types [13].

S100A14 is a member of the S100 family. Loss of expression or overexpression of S100A14 has been reported in tumors, its functional role has been proposed to be organ-specific and involved in tumorigenesis [14]. S100A14 is also a target for p53 and could alter p53 transactivity and stability, and by regulating matrix metalloproteinase (MMP)2 transcription, S100A14 affects cell invasiveness in a p53-dependent manner [15]. It is reported to be upregulated in some cancer types, including ovarian, lung, breast, uterine, and cervical cancer [12].

The aim of the current study was to investigate the clinical usefulness of the S100A14 level as a biomarker 
Table 1 Demographic data of all studied groups

\begin{tabular}{|c|c|c|c|c|c|c|c|c|c|}
\hline & & \multicolumn{2}{|c|}{$\begin{array}{l}\text { Control group } \\
(\text { no. }=20)\end{array}$} & \multicolumn{2}{|c|}{$\begin{array}{l}\text { Cirrhosis group } \\
(\text { no. }=35)\end{array}$} & \multicolumn{2}{|c|}{$\begin{array}{l}\text { HCC group } \\
\text { (no. }=35)\end{array}$} & \multicolumn{2}{|c|}{ Chi-squared test } \\
\hline & & No. & $\%$ & No. & $\%$ & No. & $\%$ & & $p$ value \\
\hline \multirow[t]{2}{*}{ Sex } & Female & 10 & $50.0 \%$ & 17 & $48.6 \%$ & 15 & $42.9 \%$ & 0.344 & 0.842 \\
\hline & Male & 10 & $50.0 \%$ & 18 & $51.4 \%$ & 20 & $57.1 \%$ & & \\
\hline \multirow[t]{2}{*}{ Age } & Mean \pm SD & \multicolumn{2}{|c|}{$29.85 \pm 8.57$} & \multicolumn{2}{|c|}{$49.97 \pm 8.13$} & \multicolumn{2}{|c|}{$54.91 \pm 5.48$} & 77.972 & $<0.001$ \\
\hline & Range & \multicolumn{2}{|c|}{$20-60$} & \multicolumn{2}{|c|}{$25-60$} & \multicolumn{2}{|c|}{$40-60$} & & \\
\hline
\end{tabular}

for hepatocellular carcinoma (HCC) among high-risk patients compared to alpha-fetoprotein (AFP).

\section{Methods}

The study was reviewed and approved by Independent Ethics Committees of National Hepatology and Tropical Medicine Research Institute (NHTMRI) number 152015 and conducted in accordance with the Declaration of Helsinki and Good Clinical Practice guidelines. All enrolled patients provided written, informed consent prior to the start of the study.

Our study has been carried out in the National Hepatology and Tropical Medicine Research Institute as a single-center prospective observational study on 90 people divided into three groups of individuals: (I) control group: 20 healthy persons aged 20 to 60 years with mean \pm SD of $29.85 \pm 8.57$ years with no evidence of liver diseases. (II) Hepatocellular carcinoma group: 35 persons of inpatients aged 40 to 60 years with mean \pm SD of $54.91 \pm 5.48$ with $\mathrm{HCC}$ with chronic hepatitis $\mathrm{C}$ (CHC) diagnosed by ultrasound, CT or MRI examinations and $\mathrm{CHC}$ diagnosis were based on anti-HCV positive by ELISA and PCR. (III) Liver cirrhosis (LC) group: 35 persons of inpatients aged 25 to 60 years with a mean \pm SD of $49.97+8.13$ with HCV-related LCdiagnosed histologically by liver biopsy and non-histologically by fibroscane by specialists.

Table $2 \mathrm{VaL}$ ) in all studied group/L) in all studied groups

\begin{tabular}{llll}
\hline S100A14(mg/L) & Groups & & \\
\cline { 2 - 4 } & $\begin{array}{l}\text { Control group } \\
(\text { no. }=20)\end{array}$ & $\begin{array}{l}\text { Cirrhosis group } \\
(\text { no. }=35)\end{array}$ & $\begin{array}{l}\text { HCC group } \\
(\text { no. }=35)\end{array}$ \\
\hline Mean \pm SD & $0.27 \pm 0.06$ & $0.29 \pm 0.08$ & $0.65 \pm 0.19$ \\
Min-max & $0.15-0.38$ & $0.2-0.47$ & $0.26-1.1$ \\
One-way ANOVA & $F \quad 84.897$ & & \\
Post hoc test & $p$ value $<0.001$ & \\
Cirrhosis group vs & $p$ value NS & \\
Control group & & \\
HCC group vs control & $p$ value $<0.001$ & \\
group & & \\
Cirrhosis group vs & $p$ value $<0.001$ & \\
HCC group & & \\
\hline
\end{tabular}

All the patients are naive and did not receive any treatment. All patients included in the study did not complain of portal vein thrombosis.

Aware acceptance from patients was gained and confirmed by the Ethical Committee of the Research of the NationalHepatology and Tropical Medicine Research Institute.

Venous blood samples were taken and centrifuged and the levels of S100A14 have been detected in serum of samples by ELISA (Glory Science Co., Ltd., USA) [16] and Alpha-fetoprotein have been detected in serum of samples by ELISA (Immunospec Corporation, USA) [17] by electrochemiluminescence immunoassay "ECLIA" Cobas e 602 immunoassay analyzers. Reference standards were used to obtain a standard curve to detect S100A14 and AFP levels in serum samples.

A combination of tests for AFP and S100A14 protein was tried to increase the accuracy and performance of the test.

\section{Data management and statistical analysis}

Data were collected, coded, revised, and entered into the Statistical Package for Social Science (IBM SPSS) version 20. The data were presented as number and percentages for the qualitative data, mean, standard deviations and ranges for the quantitative data with parametric distribution and median with interquartile range (IQR) for the

Table 3 Values of AFP in all studied groups

\begin{tabular}{|c|c|c|c|}
\hline \multirow[t]{2}{*}{ AFP(ng/ml) } & \multicolumn{3}{|l|}{ Groups } \\
\hline & $\begin{array}{l}\text { Control group } \\
(\text { no. }=20)\end{array}$ & $\begin{array}{l}\text { Cirrhosis group } \\
(\text { no. }=35)\end{array}$ & $\begin{array}{l}\text { HCC group } \\
(\text { no. }=35)\end{array}$ \\
\hline Mean \pm SD & $4.89 \pm 2.89$ & $109.91 \pm 195.84$ & $276.09 \pm 346.93$ \\
\hline Min-max & $1.0-9.37$ & $6.44-819$ & $13.5-1292.5$ \\
\hline One-way ANOVA & $\begin{array}{l}F \quad 8.333 \\
p \text { value }<0.001\end{array}$ & & \\
\hline Post hoc test & & & \\
\hline $\begin{array}{l}\text { Cirrhosis group } \\
\text { vs control group }\end{array}$ & $p$ value NS & & \\
\hline $\begin{array}{l}\text { HCC group } \\
\text { vs control group }\end{array}$ & $p$ value $<0.001$ & & \\
\hline $\begin{array}{l}\text { Cirrhosis group } \\
\text { vs HCC group }\end{array}$ & $p$ value 0.006 & & \\
\hline
\end{tabular}


Table 4 The sensitivity and specificity for S100A14

\begin{tabular}{llllll}
\hline Cut-off point & AUC & Sensitivity $\%$ & Specificity $\%$ & $-\mathrm{PV}$ & $+\mathrm{PV}$ \\
\hline$>0.47$ & 0.964 & $100.00 \%$ & $88.57 \%$ & 89.7 & 100.0 \\
\hline
\end{tabular}

quantitative data with the non-parametric distribution. Chi-square test was used in the comparison between two groups with qualitative data. Independent $t$ test was used in the comparison between two groups with quantitative data and parametric distribution. The comparison between more than two groups with quantitative data and parametric distribution was done by using one-way analysis of variance (ANOVA) test. Spearman correlation coefficients were used to assess the significant relation between two quantitative parameters in the same group. The receiver operating characteristic curve (ROC) was used to assess the best cut-off point between two groups with its sensitivity, specificity, positive predictive value (PPV), negative predictive value (NPV), and area under the curve (AUC). The confidence interval was set to $95 \%$ and the margin of error accepted was set to $5 \%$. So, the level of significance was set according to the following $p$ values: $p>0.05$ : non-significant (NS), $p<0.05$ : significant $(\mathrm{S})$, and $p<0.01$ : highly significant $(\mathrm{HS})$.

\section{Results}

The demographic data showed that there was a statistically significant increase in the age of HCC patients in comparison to cirrhosis and control groups (Table 1).

Regarding S100A14 and AFP, levels showed (Tables 2 and 3 ) that there was a statistically highly significant increase in HCC group in comparison to cirrhosis and control groups in both parameters.

From ROC curves of S100A14 and AFP in HCC group and cirrhosis group, the sensitivity and specificity for S100A14 were $100.0 \%$ and $88.57 \%$ at the cut-off point of $>0.47 \mathrm{ng} / \mathrm{ml}$ with an area under the curve (AUC) of 0.964 , while AFP yielded a sensitivity of $80 \%$ and specificity of $54.29 \%$ at the cut-off point of $0.648 \mathrm{mg} / \mathrm{dl}$ with an area under the curve (AUC) $\leq 98.15$ (Tables 4 and 5) (Figs. 1 and 2).

Table 6 shows that there was a statistically significant increase in HCC in comparison to control and cirrhosis group with SGPT, SGOT, Bilirubin total and direct but there was a statistically significant increase in control in comparison to HCC and cirrhosis group with albumin, HB, RBCs, and PLT.

Table 5 The sensitivity and specificity for AFP

\begin{tabular}{llllll}
\hline Cut-off point & AUC & Sensitivity \% & Specificity \% & -PV & + PV \\
\hline 0.648 & $\leq 98.15$ & $80.00 \%$ & $54.29 \%$ & 63.6 & 73.1 \\
\hline
\end{tabular}

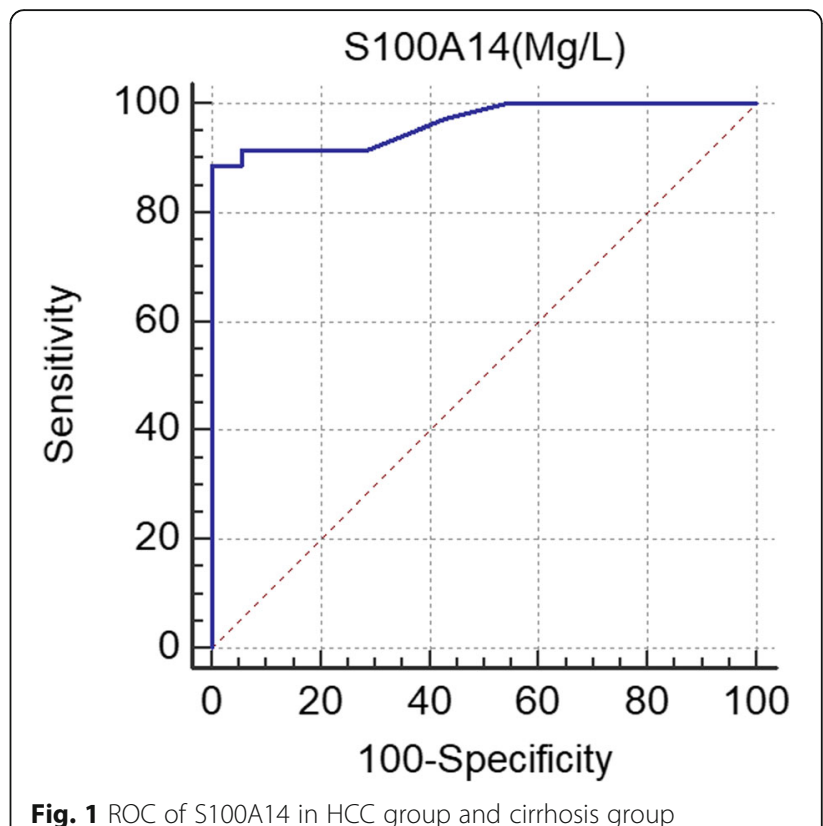

Fig. 1 ROC of S100A14 in HCC group and cirrhosis group

Distribution of stages of tumors in the HCC group (Table 7) according to the AJCC (American Joint Committee on Cancer) TNMn system, stage grouping of tumors which based on three key pieces of information:

- The size and number of tumors $(\mathrm{T})$

- The spread to nearby lymph nodes $(\mathrm{N})$

- The metastasis to distant sites (M)

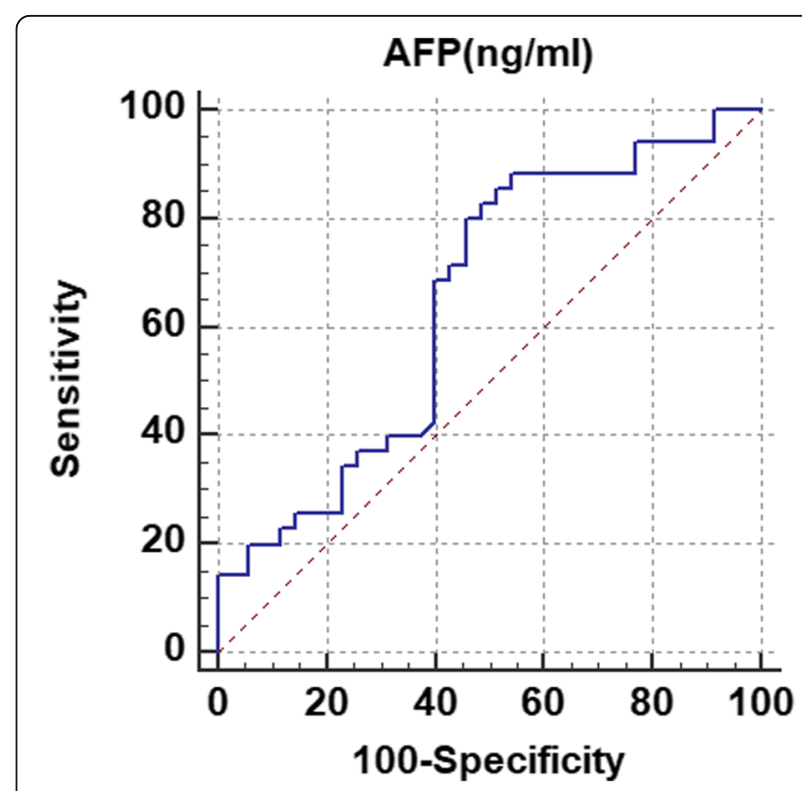

Fig. 2 ROC of AFP in HCC group and cirrhosis group 
Table 6 Data of liver function test and CBC in cirrhosis, HCC, control group

\begin{tabular}{|c|c|c|c|c|c|c|c|c|}
\hline & \multicolumn{2}{|l|}{ Cirrhosis group } & \multicolumn{2}{|l|}{ HCC group } & \multicolumn{2}{|l|}{ Control group } & \multicolumn{2}{|c|}{ One-way ANOVA } \\
\hline & Mean \pm SD & Min-max & Mean \pm SD & Min-max & Mean \pm SD & Min-max & $F$ & $p$ value \\
\hline S.GPT (U/L) & $55.91 \pm 33.84$ & $15-138$ & $66.71 \pm 43.17$ & $22-201$ & $15.35 \pm 5.37$ & $10-26$ & 14.763 & 0.001 \\
\hline S.GOT (U/L) & $84.71 \pm 49.10$ & $20-244$ & $145.77 \pm 161.89$ & $30-821$ & $18.85 \pm 6.54$ & $12-34$ & 9.371 & 0.001 \\
\hline Albumin (g/dl) & $2.40 \pm 0.61$ & $1.4-3.8$ & $2.24 \pm 0.55$ & $1.3-3.6$ & $4.34 \pm 0.31$ & $3.8-4.8$ & 112.256 & 0.001 \\
\hline Bilirubin Total (mg/dl) & $4.25 \pm 3.89$ & $0.46-20.7$ & $5.92 \pm 6.51$ & $0.6-21.5$ & $0.44 \pm 0.17$ & $0.2-0.8$ & 8.561 & 0.001 \\
\hline Bilirubin Direct (mg/dl) & $2.14 \pm 2.09$ & $0.1-10.7$ & $3.35 \pm 4.04$ & $0.2-12.8$ & $0.15 \pm 0.05$ & $0.1-0.2$ & 8.080 & 0.001 \\
\hline Hemoglobin (g/dl) & $10.23 \pm 1.99$ & $6-14.8$ & $10.97 \pm 1.42$ & $8.3-14.6$ & $12.14 \pm 1.58$ & $9.6-14.8$ & 8.046 & 0.001 \\
\hline $\operatorname{RBCs}\left(\times 10^{6} / \mu \mathrm{L}\right)$ & $3.59 \pm 0.79$ & $2.22-5.57$ & $3.86 \pm 0.58$ & $3.2-5.79$ & $4.45 \pm 0.43$ & $3.71-5.55$ & 11.384 & 0.001 \\
\hline $\operatorname{PLT}\left(\times 10^{3} / \mu \mathrm{L}\right)$ & $111.71 \pm 71.43$ & $24-342$ & $114.31 \pm 67.52$ & $18-288$ & $267.75 \pm 52.54$ & $174-356$ & 42.545 & 0.001 \\
\hline WBC $\left(\times 10^{3} / \mu \mathrm{L}\right)$ & $7.99 \pm 3.41$ & $3-15$ & $8.89 \pm 5.14$ & $2.5-18.3$ & $6.62 \pm 1.29$ & $4.2-9$ & 2.163 & 0.121 \\
\hline
\end{tabular}

This table shows that there was statistically significant increase in HCC in comparison to control and cirrhosis group with SGPT, SGOT, bilirubin total, and direct but there was statistically significant increase in control in comparison to HCC and cirrhosis group with albumin, HB, RBCs, and PLT

Table 7 shows that $17.1 \%$ was IA tumor stage, $8.6 \%$ was IB tumor stage, $37.1 \%$ was II tumor stage, $20.0 \%$ was IIIA tumor stage, and $17.1 \%$ was IIIB tumor stage.

Table 8 shows that S100A14 has a positive correlation with stage of tumors in the HCC group.

\section{Discussion}

An S100 protein family is a multigenic group of nonubiquitous cytoplasmic EF-hand Ca2+-binding proteins, sharing significant structural similarities at both genomic and protein levels. They are differentially expressed in a wide variety of cell types [18] and have been reported to be involved in the regulation of inflammatory responses, [19] as well as in the metastasis development of several cancers [20].

S100A14, a member of the S100 family, is involved in several vital functional and pathological processes [21]. S100A14 was reported to be upregulated in several tumor types, including ovarian, lung, breast, and uterine cancer, but downregulated in others, such as kidney, colon, rectal, and esophageal cancer [14]. S100A14 can regulate oral squamous cell carcinoma cell invasion by modulating the expression of matrix metalloproteinase (MMP)-1 and MMP-9 [16].

Regarding the demographic data in the present study, there was statistically significant difference between groups as regards mean of age $(p<0.001)$ with increase in HCC $(54.91 \pm 5.48)$ in comparison to cirrhosis $(49.97 \pm 8.13)$ and control group (29.85 \pm 8.57) but no statistically significant in sex as regards studied groups while male was more than females among groups. This is similar to Choi et al .[22] study in which mean age of cirrhosis group was $54.3 \pm 8.6$ whereas in the HCC group was $61.2 \pm 9.3$ with a statistically significant difference while male to female ratio were $34 / 2$ and $86 / 21$.

The effect of S100A14 on tumor metastasis remains controversial. Elevated S100A14 promotes the metastasis of tumor cells and induces worse survival in hepatocellular carcinoma [23]. This is consistent with the results of

Table 7 Distribution of stages of tumors in HCC group according to the AJCC

\begin{tabular}{|c|c|c|c|c|}
\hline AJCC stage & Stage grouping & Stage description & No & $\%$ \\
\hline IA & $\begin{array}{l}\text { T1a } \\
\text { N0 } \\
\text { M0 }\end{array}$ & $\begin{array}{l}\text { A single tumor } 2 \mathrm{~cm}(4 / 5 \mathrm{in} \text {.) or smaller that has not grown into blood vessels (T1a). } \\
\text { It has not spread to nearby lymph nodes (N0) or to distant sites (MO). }\end{array}$ & 6 & $17.1 \%$ \\
\hline IB & $\begin{array}{l}\text { T1b } \\
\text { NO } \\
\text { MO }\end{array}$ & $\begin{array}{l}\text { A single tumor larger than } 2 \mathrm{~cm}(4 / 5 \mathrm{in} \text {.) that has not grown into blood vessels (T1b). } \\
\text { The cancer has not spread to nearby lymph nodes (NO) or to distant sites (M0). }\end{array}$ & 3 & $8.6 \%$ \\
\hline II & $\begin{array}{l}\text { T2 } \\
\text { N0 } \\
\text { M0 }\end{array}$ & $\begin{array}{l}\text { Either a single tumor larger than } 2 \mathrm{~cm}(4 / 5 \mathrm{in} \text {.) that has grown into blood vessels, } \\
\text { OR more than one tumor but none larger than } 5 \mathrm{~cm} \text { (about } 2 \mathrm{in} \text {.) across (T2). } \\
\text { It has not spread to nearby lymph nodes (N0) or to distant sites (M0). }\end{array}$ & 13 & $37.1 \%$ \\
\hline IIIA & $\begin{array}{l}\text { T3 } \\
\text { NO } \\
\text { MO }\end{array}$ & $\begin{array}{l}\text { More than one tumor, with at least one tumor larger than } 5 \mathrm{~cm} \text { across (T3). } \\
\text { It has not spread to nearby lymph nodes (N0) or to distant sites (M0). }\end{array}$ & 7 & $20.0 \%$ \\
\hline IIIB & $\begin{array}{l}\text { T4 } \\
\text { N0 } \\
\text { MO }\end{array}$ & $\begin{array}{l}\text { At least one tumor (any size) that has grown into a major branch of a large vein of } \\
\text { the liver (the portal or hepatic vein) (T4). } \\
\text { It has not spread to nearby lymph nodes (NO) or to distant sites (MO). }\end{array}$ & 6 & $17.1 \%$ \\
\hline
\end{tabular}

This Table 7 shows that $17.1 \%$ was IA tumor stage, $8.6 \%$ was IB tumor stage, $37.1 \%$ was II tumor stage, $20.0 \%$ was IIIA tumor stage, and $17.1 \%$ was IIIB tumor stage 
Table 8 Relation between S100A14 as regards stage of tumors in HCC group

\begin{tabular}{llll}
\hline AJCC & S100A14 $(\mathrm{mg} / \mathrm{L})$ & \multicolumn{2}{l}{ One-way ANOVA } \\
\cline { 3 - 4 } stage & Mean \pm SD & $f$ & $p$ value \\
\hline IA & $0.38 \pm 0.12$ & 17.716 & $<0.001$ \\
IB & $0.57 \pm 0.06$ & & \\
$\|$ & $0.64 \pm 0.09$ & & \\
IIIA & $0.78 \pm 0.05$ & & \\
IIIB & $0.86 \pm 0.18$ & &
\end{tabular}

This table shows that S100A14 has positive correlation with stage of tumors in HCC group

the present study in which there was a statistically significant increase in HCC in comparison to cirrhosis and control group with S100A14 with the highest mean among HCC group $(0.65 \pm 0.19)$.

Previous studies found that elevated AFP levels are associated with higher pathological grade [24, 25]. AFP measurements among groups of the current study showed a statistically significant difference between groups regarding AFP which increased in HCC in comparison to cirrhosis and control group with the highest mean among HCC group (276.09 \pm 346.93$)$. This is in agreement with Luo et al. [26] study in which the mean among HCC group was 306.6 and in cirrhosis group 238.5. In this study, ROC area under the curve for AFP was $\leq 98.15$ at 0.648 points AFP had $80 \%$ sensitivity, 54.29\% specificity, 73.1\% PPV, and 63.6\% NPV.

The role of S100A14 in sustaining HCC proliferation, migration, and invasion were confirmed in HCC cell culture and in vivo (mice) analysis, thus supporting the role of S100A14 in sustaining HCC metastasis [23]. In the current study, S100A14 at 0.47 point or less S100A14 had 100\% sensitivity, $88.57 \%$ specificity, $100 \% \mathrm{PPV}$, and $89.7 \% \mathrm{NPV}$.

Zhao et al. [23] used an extensive collection of HCC tumors to show that S100A14 was significantly elevated in HCC tissues. The increased S100A14 expression was correlated with multiple tumor nodes, high EdmondsonSteiner grade, and vascular invasion. These observations were reminiscent of previous reports in other malignancies such as esophageal squamous cell carcinoma [27] and colorectal cancer [28].

This study shows that protein S100A14 is a more sensitive and specific biomarker for the diagnosis of HCC disease in comparison to AFP.

\section{Conclusion}

Protein S100A14 have been reported to be involved in the regulation of inflammatory responses, as well as in the metastasis development of several cancers. Protein S100A14 is a more sensitive and specific biomarker for the diagnosis of HCC disease in comparison to AFP. It fair to say that S100A14 is a good diagnostic marker for HCC

\section{Abbreviations}

HCC: Hepatocellular carcinoma; AFP: Alpha-fetoprotein

\section{Acknowledgements}

We acknowledge all physicians in National Hepatology and Tropical Medicine Research Institute for their help in sample collection and study.

\section{Authors' contributions}

$\mathrm{BF}$, the main author, ran the chemical tests over the serum samples to detect levels of AFP and Protein S100A14. She also wrote the manuscript. WS was responsible for analyzing samples with basma and statistical analysis of the results. RA was responsible for analyzing the samples with basma and statistical analysis of the results. HF was responsible for choosing patients with cirrhosis and HCC. She was also responsible for clinical assessment of the patients and extracting the venous samples. All authors have read and approved the manuscript.

\section{Funding}

The authors declare that they did not have any financial support or grants and have no conflict of interest regarding the publication of this article.

\section{Availability of data and materials}

All data generated or analyzed during this study are included in this published article [and its supplementary information files].

\section{Ethics approval and consent to participate}

The study was reviewed and approved by Independent Ethics Committees of national hepatology and tropical medicine research institute (NHTMRI) number 15-2015 and conducted in accordance with the Declaration of Helsinki and Good Clinical Practice guidelines. All enrolled patients provided written, informed consent prior to the start of the study.

\section{Consent for publication}

Not applicable

\section{Competing interests}

Authors declare no competing interests.

\section{Author details}

${ }^{1}$ Biochemist, Suez Hospital for Health Insurance, Suez, Egypt. ${ }^{2}$ Assistant professor of Biochemistry, Chemistry Department, Faculty of Science, Suez University, Suez, Egypt. ${ }^{3}$ Professor of Organic Chemistry, Chemistry Department, Faculty of Science, Suez, Egypt. ${ }^{4}$ Assistant professor of Hepatology and Gastroenterology, National Hepatology and Tropical Medicine Research Institute, Cairo, Egypt.

Received: 19 August 2019 Accepted: 12 December 2019

Published online: 20 December 2019

\section{References}

1. Jemal A, Bray F, Center MM, Ferlay J, Ward E, Forman D (2011) Global cancer statistics. CA: a cancer journal for clinicians. 61(2):69-90

2. Gao J, Xie L, Yang W-S, Zhang W, Gao S, Wang J et al (2012) Risk factors of hepatocellular carcinoma--current status and perspectives. Asian Pac J Cancer Prev. 13(3):743-752

3. McClune AC, Tong MJ (2010) Chronic hepatitis B and hepatocellular carcinoma. Clinics in liver disease. 14(3):461-476

4. Szklaruk J, Silverman PM, Charnsangavej C (2003) Imaging in the diagnosis, staging, treatment, and surveillance of hepatocellular carcinoma. American Journal of Roentgenology. 180(2):441-454

5. Johnson PJ (2001) The role of serum alpha-fetoprotein estimation in the diagnosis and management of hepatocellular carcinoma. Clinics in liver disease. 5(1):145-159

6. Malaguarnera M, Di Rosa M, Nicoletti F, Malaguarnera L (2009) Molecular mechanisms involved in NAFLD progression. Journal of molecular medicine. 87(7):679

7. Malaguarnera L, Madeddu R, Palio E, Arena N, Malaguarnera M (2005) Heme oxygenase-1 levels and oxidative stress-related parameters in non-alcoholic fatty liver disease patients. Journal of hepatology. 42(4):585-591

8. Singal A, Volk M, Waljee A, Salgia R, Higgins P, Rogers M et al (2009) Metaanalysis: surveillance with ultrasound for early-stage hepatocellular 
carcinoma in patients with cirrhosis. Alimentary pharmacology \& therapeutics. 30(1):37-47

9. Lok AS, Sterling RK, Everhart JE, Wright EC, Hoefs JC, Di Bisceglie AM et al (2010) Des- $\psi$-carboxy prothrombin and a-fetoprotein as biomarkers for the early detection of hepatocellular carcinoma. Gastroenterology. 138(2):493-502

10. Terentiev A, Moldogazieva N (2006) Structural and functional mapping of afetoprotein. Biochemistry (Moscow). 71(2):120-132

11. Zhu M, Wang H, Cui J, Li W, An G, Pan Y et al (2017) Calcium-binding protein S100A14 induces differentiation and suppresses metastasis in gastric cancer. Cell death \& disease. 8(7):e2938

12. Wang X, Yang J, Qian J, Liu Z, Chen H, Cui Z (2015) S100A14, a mediator of epithelial-mesenchymal transition, regulates proliferation, migration and invasion of human cervical cancer cells. American journal of cancer research. 5(4):1484

13. Tanaka M, Ichikawa-Tomikawa N, Shishito N, Nishiura K, Miura T, Hozumi A et al (2015) Co-expression of S100A14 and S100A16 correlates with a poor prognosis in human breast cancer and promotes cancer cell invasion. BMC cancer. 15(1):53

14. Ehmsen S, Hansen LT, Bak M, Brasch-Andersen C, Ditzel HJ, Leth-Larsen R (2015) S $100 \mathrm{~A} 14$ is a novel independent prognostic biomarker in the triple-negative breast cancer subtype. International journal of cancer. 137(9):2093-2103

15. Zhao Y, Yao F, Tang W, Gu H, Zhao H (2017) S100A14 rs11548103 G> A polymorphism is associated with a decreased risk of esophageal cancer in a Chinese population. Oncotarget. 8(49):86917

16. Pietas A, Schlüns K, Marenholz I, Schäfer BW, Heizmann CW, Petersen I (2002) Molecular cloning and characterization of the human S100A14 gene encoding a novel member of the $\$ 100$ family. Genomics. 79(4):513-522

17. SL S (1990) Cancer markers of the 1990s. Clin Lab Med 10:1-37

18. Schäfer BW, Heizmann CW (1996) The S100 family of EF-hand calciumbinding proteins: functions and pathology. Trends in biochemical sciences. 21(4):134-140

19. Nacken W, Roth J, Sorg C, Kerkhoff C (2003) S100A9/S100A8: Myeloid representatives of the $\mathbf{S} 100$ protein family as prominent players in innate immunity. Microscopy research and technique. 60(6):569-580

20. Ghavami S, Chitayat S, Hashemi M, Eshraghi M, Chazin WJ, Halayko AJ et a (2009) S100A8/A9: a Janus-faced molecule in cancer therapy and tumorgenesis. European journal of pharmacology. 625(1-3):73-83

21. Bertini I, Borsi V, Cerofolini L, Gupta SD, Fragai M, Luchinat C (2013) Solution structure and dynamics of human S100A14. JBIC Journal of Biological Inorganic Chemistry. 18(2):183-194

22. Choi SH, Choi GH, Kim SU, Park JY, Joo DJ, Ju MK et al (2013) Role of surgical resection for multiple hepatocellular carcinomas. World journal of gastroenterology: WJG. 19(3):366

23. Zhao F-T, Jia Z-S, Yang Q, Song L, Jiang X-J (2013) S100A14 promotes the growth and metastasis of hepatocellular carcinoma. Asian Pacific Journal of Cancer Prevention. 14(6):3831-3836

24. Everhart JE, Wright EC, Goodman ZD, Dienstag JL, Hoefs JC, Kleiner DE et al (2010) Prognostic value of Ishak fibrosis stage: Findings from the hepatitis $C$ antiviral long-term treatment against cirrhosis trial. Hepatology. 51(2):585-594

25. Rozario R, Ramakrishna B (2003) Histopathological study of chronic hepatitis $B$ and $C$ : a comparison of two scoring systems. Journal of hepatology. 38(2):223-229

26. Luo J, Peng Z-W, Guo R-P, Zhang Y-Q, Li J-Q, Chen M-S et al (2011) Hepatic resection versus transarterial lipiodol chemoembolization as the initial treatment for large, multiple, and resectable hepatocellular carcinomas: a prospective nonrandomized analysis. Radiology. 259(1):286-295

27. Chen H, Yuan Y, Zhang C, Luo A, Ding F, Ma J et al (2012) Involvement of S100A14 protein in cell invasion by affecting expression and function of matrix metalloproteinase (MMP)-2 via p53-dependent transcriptiona regulation. Journal of Biological Chemistry. 287(21):17109-17119

28. Wang H-Y, Zhang J-Y, Cui J-T, Tan X-H, Li W-M, Gu J et al (2010) Expression status of S100A14 and S100A4 correlates with metastatic potential and clinical outcome in colorectal cancer after surgery. Oncology reports. 23(1):45-52

\section{Publisher's Note}

Springer Nature remains neutral with regard to jurisdictional claims in published maps and institutional affiliations.

\section{Submit your manuscript to a SpringerOpen ${ }^{\circ}$ journal and benefit from:}

- Convenient online submission

- Rigorous peer review

- Open access: articles freely available online

- High visibility within the field

- Retaining the copyright to your article

Submit your next manuscript at $\boldsymbol{\nabla}$ springeropen.com 